\title{
ENGLISH CONVERSATION CLASS (ECC) UNTUK MENCIPTAKAN ENGLISH ENVIRONMENT DI SMA ISLAM NUSANTARA (SMAINUS)
}

\author{
Kurniasih ${ }^{1}$, Nuse Aliyah Rahmati ${ }^{2}$, Atik Umamah ${ }^{3}$, Diah Retno Widowati ${ }^{4}$ \\ ${ }^{1}$ Universitas Islam Malang \\ email: kurniasih@unisma.ac.id \\ 2Universitas Islam Malang \\ email: nuse.rahmati@unisma.ac.id \\ ${ }^{3}$ Universitas Islam Malang \\ email: atikumamah@unisma.ac.id \\ ${ }^{4}$ Universitas Islam Malang \\ email: d.retnowidowati@unisma.ac.id
}

\begin{abstract}
The teaching of English in Indonesia has been started from elementary school until university level because students are expected to have good knowledge of English as the international language. In order to compete with people all over the world, English learners should be able to use English both in written and spoken form. The teaching of English in SMAINUS has been conducted in a fun way supported by the innovative teacher and interactive technique. Consequently, students have positive perceptions toward English and are more motivated to improve their English. However, there is no any English club, especially on English Conversation Club (ECC) that can facilitate students to do speaking practice outside the class to improve their productive skill rapidly. Therefore, this program is the starting point of ECC in SMAINUS. This paper aims at exploiting students' perceptions of ECC program to create English environment.
\end{abstract} Keywords: conversation, english environment

\begin{abstract}
ABSTRAK
Pembelajaran Bahasa Inggris di Indonesia dimulai dari sekolah dasar sampai tingkat universitas karena peserta didik diharapkan mampu menguasai Bahasa Inggris sebagai bahasa internasional. Untuk mampu bersaing dengan negara lain, pebelajar bahasa harus mampu menggunakan Bahasa Inggris baik secara lisan maupun tulisan. Pembelajaran Bahasa Inggris di SMAINUS sudah dilakukan dengan baik, proses pembelajaran didukung oleh guru yang inovatif dengan menggunakan berbagai teknik pembelajaran yang menarik dan media pembelajaran yang interaktif. Sehingga siswa terpacu dan memiliki sikap yang positif terhadap Bahasa Inggris. Kendala yang dihadapi adalah belum terbentuknya English Conversation Class (ECC) untuk mewadahi minat siswa untuk meningkatkan kemampuan berbicara Bahasa Inggris. Diharapkan ECC dapat memberikan kesempatan yang lebih banyak kepada siswa untuk mempraktikan atau menggunakan Bahasa Inggris diluar kelas, sehingga membantu penguasaan bahasa inggris untuk meningkatkan productive skill lebih cepat.Maka dari itu, program ini dilakukan sebagai inisiasi pembentukan ECC di SMAINUS. Artikel ini memaparkan persepsi siswa terhadap kegiatan ECC untuk menciptakan English environment.
\end{abstract}

Kata Kunci: percakapan, lingkungan bahasa Inggris 


\section{PENDAHULUAN}

SMA Islam Nusantara d.h SMA Wahid Hasyim adalah sekolah yang swasta dikota Malang yang berlokasi di jalan Mayjen Haryono XIX-XXI/30 Dinoyo Permai Malang. SMA Islam Nusantara lebih dikenal dengan nama SMAINUS dan merupakan sekolah laboratorium (Lab School) UNISMA karena berada dalam yayasan Universitas Islam Malang. Dengan mengusung konsep "Islamic Entrepreneurial School" (sekolah berkonsep kewirausahaan Islami) yang mendidik dan menciptakan wirausaha Islami yang berhaluan Ahlusunna Wal Jamaah (Aswaja) diharapkan siswa memiliki jiwa kewirausahaan yang tinggi sehingga mereka siap dan mampu bersaing setelah mereka lulus.

Pembelajaran Bahasa Inggris dikemas sangat menarik dengan didukung oleh media pembelajaran interaktif. Hal ini berdampak dalam membentuk sikap positif siswa terhadap Bahasa Inggris. Masalah yang dihadapi oleh siswa adalah belum terbentuknya English Club untuk memfasilitasi siswa yang berminat untuk memperdalam bahasa Inggris, dan diperlukan pendampingan intensif sehingga program ini berhasil. Berdasarkan paparan diatas bisa disimpulkan bahwa program peningkatan kemampuan berbicara bahasa Inggris penting untuk dilaksanakan sehingga siswa mampu menggunakan bahasa Inggris secara produktif. Penelitian yang dilakukan oleh Kurniawan, Herpratiwi \& Purnomo (2015) membuktikan bahwa hasil belajar siswa yang mengikuti program English Club dan English Fun Day meningkat hasil belajar bahasa Inggris masing-masing $22 \%$ dan $20 \%$. Hal ini membuktikan bahwa kegiatan ekstrakulikuler bahasa Inggris menberikan dampak yang positi terhadap peningkatan kemampuan bahasa Inggris.

Kegiatan ECC dikemas dengan mengintegrasikan game, media, dan teknik pembelajaran yang menarik. Penggunaan game dalam pembelajaran dikelas sesuai dengan karakteristik anak usia remaja yang pada dasarnya lebih suka aktivitas belajar yang melibatkan gerakan (Ellis, 1994). Oleh karena itu kegiatan dalam program ini lebih banyak menggunakan game sebagai kegiatan inti untuk memberikan kesempatan untuk menggunakan bahasa Inggris secara aktif.

Selain itu, tutor juga menyiapkan media pembelajaran berupa lagu yang disesuikan dengan topic. Saricoba dan Metin (2000) menjelaskan bahwa lagu merupakan media yang efektif untuk digunakan dalam proses pembelajaran karena lagu "... provide frequent repetitions, or tell a story, or provide comments about life, or introduce cultural themes". Lagu merupakan salah satu jenis authentic materials yang memiliki banyak manfaat baik dalam sisi kebahasaan; peningkatan kosa kata dan penguasaan grammar maupun non kebahasaan; meningkatkan motivasi belajar dan menciptakan suasana yang menyenangkan. Kurniasih \& Umamah(2013) menjelaskan bahwa authentic materials membantu siswa memahami gammar dengan mudah karena authentic materials memberikan contoh penggunaan bahasa Inggris, misal grammar, dalam dunia nyata. Jadi, kegiatan dikelas yang dilakukan dengan “...marrying student's 
affective side and the positive effects of authentic materials would be a great combination to achieve successful grammar mastery".

Berdarkan penjelasan diatas, dapat disimpulkan bahwa program ini dilakukan sebagai inisiasi pembentukan ECC di SMAINUS untuk memberikan kesempatan kepada siswa menggunakan bahasa Inggris diluar kelas dan mendapatkan input yang baik dari kegiatan ini. Selain itu, artikel ini juga akan dipaparkan secara detail proses pembelajaran dan persepsi siswa terhadap kegiatan ECC.

\section{METODE PELAKSANAAN}

Dalam pelaksanaan program ini dilakukan dalam bentuk kegiatan pembelajaran bahasa Inggris yang dilakukan dalam bentuk ECC mulai tanggal 13 s.d. 31 Agustus 2018, dilaksanakan setelah jam sekolah mulai pukul 14.30 s.d.16.00. Secara umum ECC dilaksanakan dalam empat kegiatan, yaitu:

1. menjelaskan materi yang akan dipelajari

2. tanya jawab tentang materi yang dipelajari

3. memberikan kesempatan bagi siswa untuk mempraktikkan materi-materi yang telah dipelajari

4. melakukan pendampingan terhadap kegiatan/pembelajaran bahasa inggris disekolah mitra

Untuk mensukseskan kegiatan ECC, empat mahasiswa jurusan bahasa Inggris dari semester 8 yang bertugas menjadi tutor pendamping selama kegiatan berlangsung. Adapun kegiatan dikelas dikemas dalam kegiatan yang menarik seperti permainan, menggunakan lagu, video, dan lain-lain. yang akan digunakan diambil dari berbagai sumber, diantaranya video, lagu, dan lain sebagainya dan didukung dengan metode yang menarik untuk memotivasi siswa.

\section{HASIL DAN PEMBAHASAN}

Proses perekrutan peserta dilakukan dengan bantuan guru bahasa Inggris untuk mensosialilisasikan program ECC ke siswa kelas X, XI, XII. Siswa yang berminat diminta untuk mendaftarkan diri kepada guru bahasa Inggris. Total ada 30 siswa yang mengikuti ECC. Kegiatan pelatihan ini diawali dengan mengisi surat pernyataan kesediaan yang ditandatangani oleh peserta supaya mereka berkomitmen untuk mengikuti kegiatan pelatihan bahasa Inggris.

\section{Materi Kegiatan}

Materi yang dipelajari meliputi Siswa diminta untuk memperkenalkan diri sendiri dan orang lain dengan terlebih dahulu memahami poin-poin inti yang harus disebutkan ketika perkenalan, seperti dijelaskan dalam gambar dibawah ini: 


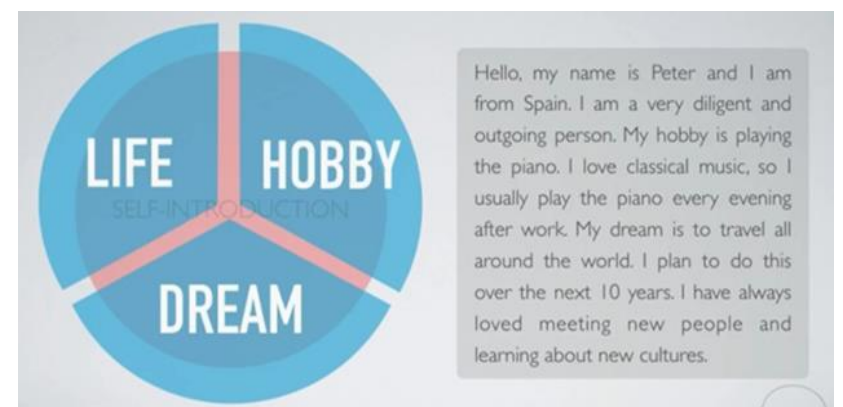

Gambar 1. materi untuk Self Introduction Oneself and Others (diambil dari Youtube)

Setelah kegiatan ini siswa diminta untuk melengkapi tabel yang berisi informasi tentang 'Life. Hobby. and Dream' dengan bermain game 'Rolling Chain'. Sebelum melakukan kegiatan tersebut siswa sudah mempraktekkan bagaimana cara bertanya tentang 'Life, Hobby, dan Dream' dalam bahasa Inggris sekaligus meresponnya. Siswa dibagi menjadi tiga kelompok, mereka berdiri melingkari meja dan menginterview siswa yang berada didepannya. Mereka bisa mulai interview setelah tutor memberikan instruksi 'START' dan mengakhiri interviewdan bergeser posisi setelah tutor memberikan instruksi 'STOP' and 'CHANGE YOUR $P O S I T I O N$ '. Kegiatan berlanjut sampai semua siswa mendapatkan informasi dari semua angota kelompok. Perwakilan kelompok mempresentasikan hasil interview secara bergantian

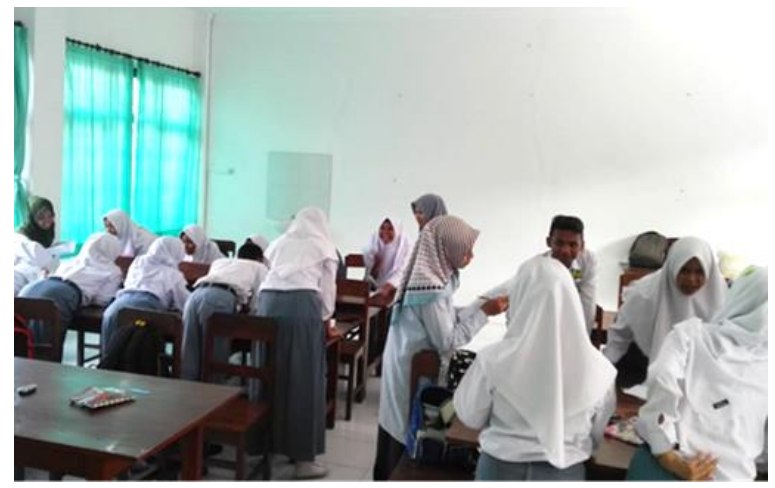

Gambar 2. Rolling Chain Game (Dokumen pribadi, 2018)

Kegiatan yang selanjutnya adalah Asking and Giving Opinion, dalam kegiatan ini siswa dilatih untuk menggunakan ungkapan untuk meminta dan memberikan pendapat. Untuk memperdalam kegiatan ini, siswa diajak bermain True and False Opinion Game. Siswa dibagi kedalam kelompok dan setiap anggota kelompok mendapatkan foto yang berbeda. gambar publik figur dan foto guru disekolah ini agar lebih kontektual dan lebih mudah bagi siswa untuk memberikan pendapat. Secara begiliran, 
siswa menyampaikan pendapatnya tentang figur dalam gambar. Siswa yang bertugas menyatakan pendapatnya bisa memilih untuk menceritakan keadaan yang sebenarnya (telling the truth) atau keadaan sebaliknya (telling a lie). Anggota kelompok harus menebak apakah siswa tersebut telling the truth atau telling a lie.

Conditional Sentence, dalam kegiatan ini diawali dengan melengkapi lirik lagu 'Count on Me' yang dipopulerkan oleh Bruno Mars. Pemilihan lagu ini karena sesuai dengan topik yang akan dibahas. Kegiatan selanjutnya adalah guru mengarahkan siswa untuk menganalisa lirik lagu dan menemukan struktur bahasa yang digunakan dalam lagu tersebut. Setelah diberikan diberikan stimulasi siswa mampu menarik kesimpulan bahwa struktur bahasa yang digunakan adalah 'Conditional Sentence'. Kegiatan ini dilanjutkan dengan memberikan penjelasan yang detail tentang Conditional sentence type I, II, and III. Untuk mengetahui pemahaman mereka, guru mengajak siswa bermain game dengan duduk melingkar. Siswa A membuat satu kalimat, misal 'If I have enough money, I will buy a car'. Siswa B melanjutkan 'If I have a car, I will visit my family in Surabaya'. Siswa C melanjutkan kalimat tersebut sampai semua siswa mendapatkan giliran.

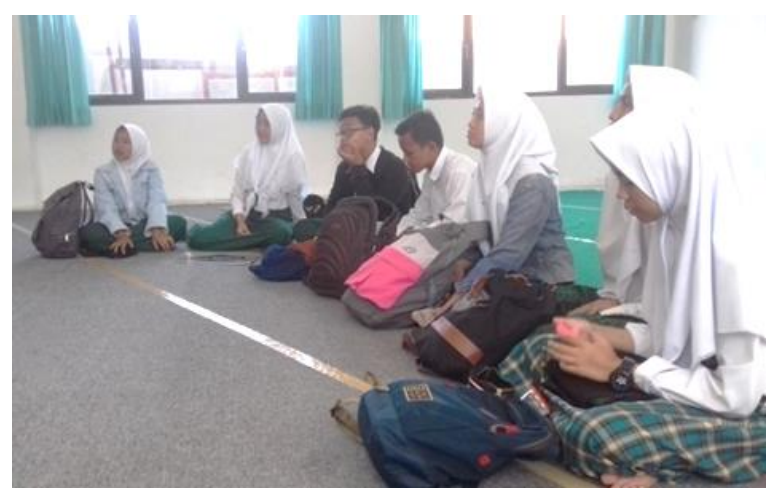

Gambar 3. menyimak penjelasan tentang 'Conditional Sentence' (Dokumen Pribadi)

Describing people. Dalam topik ini siswa belajar cara mendeskripsikan orang lain dengan menggunakan kata sifat yang tepat, misal yang berhubungan dengan appearance, characteristic, profession, dan lain-lain. Kemudian siswa diajak bermain game 'who am l' untuk menebak gambar public figure yang sedang dideskripsikan. Publik figure yang dipilih Joko Widodo, BJ Habibie, Agnes Monica, Pemain sepak bola Cristiano Ronaldo, dan Pemain Badminton Jonatan Christie. Siswa bekerja dalam kelompok untuk medeskripsikan salah satu gambar yang diberikan secara acak. Siswa diberikan daftar kosakata yang tidak pernah mereka gunakan sebelumnya seperti plump, pointed, bald, skinny, straight, fashionale, well-dressed, lanky, petiti, well-built, nasty, gregarious, down- 
to-earth, chatty dan dignified. Setelah diskusi selesai, perwakilan kelompok diminta untuk mendeskripsikan public figure didepan kelas secara bergantian, dan kelompok yang lain harus menebak publik figur yang sedang dideskripsikan.

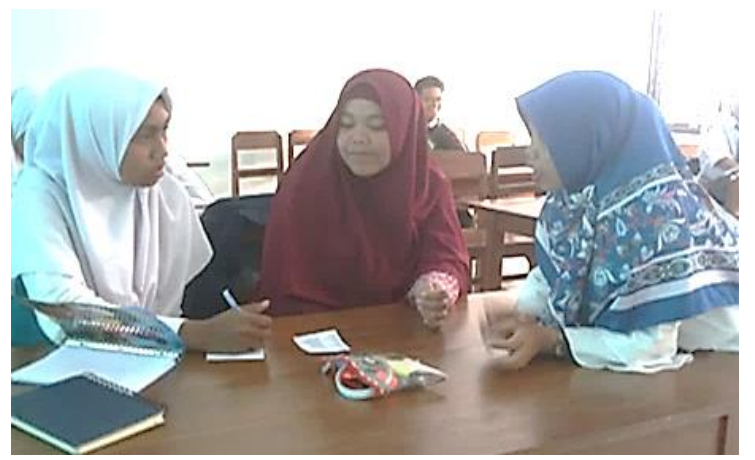

Gambar 4. Mendiskusikan Ciri-Ciri Publik Figur (Dokumen pribadi)

How to Make Something (Procedure Text). Pembelajaran teks prosedur yang dikemas dalam bentuk kegiatan 'cooking class' membuat tiga menu makanan, yaitu fruit salad, sandwich, dan cocktail. Konsep dari kegiatan ini seperti acara 'Master Chef' disalah satu stasiun TV swasta di Indonesia. Siswa dibagi menjadi tiga kelompok untuk membuat menu yang berbeda. Tiga wadah tertutup berisi alat dan bahan sudah disiapak dimeja depan, perwakilan kelompok maju kedepan memilih box secara acak. Setelah semua siswa siap, salah satu anggota kelompok mengambil video seperti vlogger untuk menjelaskan alat dan bahan yang digunakan dan untuk menjelaskan langkah-langkah membuat menu makanan. Anggota kelompok lain mengolah bahan sesuai dengan instruksi yang diberikan temannya, dan mereka bisa bertukar peran agar semua anggota kelompok aktif menggunakan bahasa Inggris.

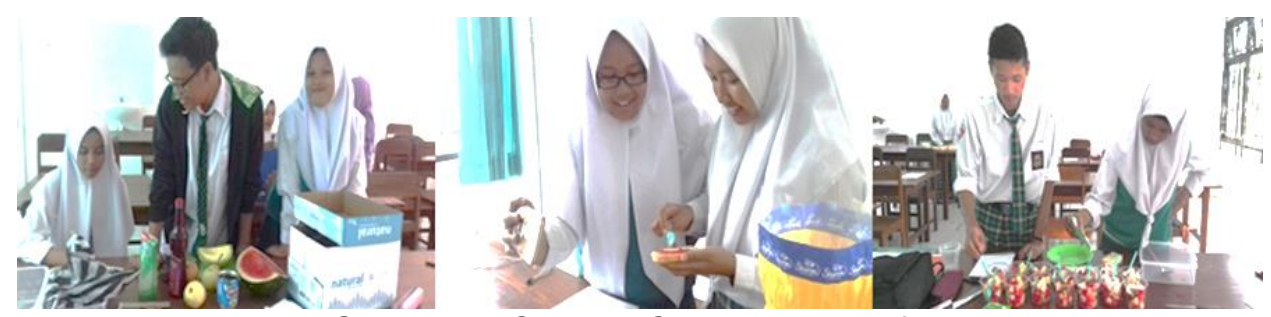

Gambar 5. Cooking Class membuat fruit salad, sandwich, dan cocktail (Dokumen Pribadi)

Tujuan utama dalam kegiatan ini adalah memberikan wadah bagi siswa yang tertarik untuk meningkatkan kemampuan berbicara bahasa Inggris. Diharapkan luaran dari kegiatan ini data meningkatkan motivasi, rasa percaya diri, dan secara tidak langsung kemampuan berbicara bahasa Inggris mereka meningkat. 


\section{Peningkatan Rasa Percaya Diri}

Berdasarkan data yang diperoleh dari hasil dari interview menunjukkan bahwa mayoritas peserta memberikan respon yang positif terhadap kegiatan ECC. Hal ini sejalan dengan pendapat yang dikemukakan oleh Peserta A yang merasakan manfaat yang luar biasa dari kegiatan ECC, dia menyatakan bahwa "saya merasa kemampuan saya dalam bahasa Inggris mulai sedikit demi sedikit meningkat". Dia juga menambahkan bahwa setelah kegiatan ini "saya lebih percaya diri saat mengirim e-mail dengan teman saya diluar negeri". Dari penyataan tersebut membuktikan bahwa hasil dari kegiatan ini tidak hanya meningkatkan kemampuan berbicara, akan tetapi juga meningkatkan kemampuan menulis.

Manfaat lain dari kegiatan ECC dapat meningkatkan rasa percaya diri seperti yang diungkapkan oleh Peserta $D$ bahwa "sebelum saya ikut kelas bahasa Inggris, saya anaknya canggung malu ndak pandai bahasa inggris, tapi sesudah saya ikut kelas bahasa inggris rasa canggung saya menghilang perlahan dan saya dapat mengenal banyak teman dan saya bisa belajar bahasa inggris". Penyataan tersebuh didukung oleh pendapat dari peserta $\mathrm{A}$, dia menambahkan bahwa "seandainya kegiatan bahasa Inggris berlanjut, mungkin saya akan lebih percaya diri. Saya sangat berterima kasih atas ilmu yang telah diberikan".

\section{Kegiatan Pembelajaran yang Menyenangkan}

Selama kegiatan ECC, tutor lebih banyak menggunakan bahasa Inggris, dengan tujuan untuk memberikan input danmenciptakan English environment. Poin ini mendapatkan tanggapan yang positif dari Peserta $\mathrm{B}$ yang menyatakan bahwa "In my opinion about English Class, it's very fun. Before I took an English class, I felt so less confident in English, I'm afraid if I have a many wrong words about what I'm speaking. But, actually l'm like English class very much. In English class, always used full English for speaking. And because of that, I can study how to speaking English with correctly".

Satu poin penting dari pernyataan diatas kelas bahasa Inggris sangat menyenangkan karena kegiatan ECC menggunakan game, media, dan teknik yang menyenangkan. Hal ini sejalan dengan hasil penelitian yang dilakukan oleh Istirokhah (2010) dan Mega (2012) tentang penggunaan lagu untuk meningkatkan penguasaan tata bahasa menunjukkan hasil yang positif. Selain itu, lagu memberikan manfaat yang luar biasa, seperti menambah kosakata, membantu penguasaan tata bahasa, membuat siswa lebih antusias, dan menciptakan suasana kelas yang menyenangkan.

Disisi lain, salah satu peserta menyatakan bahwa penggunaan bahasa Inggis didalam kelas membuatnya merasa bosan karena ada beberapa kata-kata yang sulit untuk dipahami, Peserta $C$ menyatakan 
bahwa "in my opinion about last week's English lesson it was fun but sometime there was a feeling of boredom because there only English words that were difficult to understand until it made it lazy to learn those words".

Dari dua pendapat diatas dapat disimpulkan bahwa penggunaan bahasa Indonesia masih dibutuhkan untuk membantu peserta memahami konsep dan instruksi selama kegiatan ECC. Ada salah satu peserta selama ini tidak pernah hadir dan hadir dalam pertemuan terakhir, dia menyatakan bahwa "saya dapat ilmunya.... ngajarnya seru enak...eman (sayang) yang nggak ikut...ya enak bu saya suka". Dari respon yang diberikan oleh peserta menunjukkan bahwa kegiatan pelatihan bahasa Inggris yang mendapatkan respon yang positif dari sebagian besar peserta dan mengharapkan kegiatan serupa bisa dilakukan lagi diwaktu waktu mendatang.

Untuk meningkatkan kemampuan berbicara bahasa Inggris diperlukan komunitas bahasa yang mendukung proses belajar bahasa, karena seseorang bisa belajar bahasa dengan baik dan lancer apabila didukung oleh komunitas yang memiliki tujuan yang sama. Siswa bisa mendapatkan kesempatan yang cukup dan memiliki partner untuk praktek bahasa Inggris sehingga mereka semakin lancar dalam berbicara bahasa Inggris.

\section{Kendala dan solusi permasalah}

a. Tidak semua peserta hadir dalam setiap pertemua karena ECC dilaksanakan setelah jam sekolah, jadi banyak siswa yang memilih pulang karena sudah capek sbelajar dari pagi sampai siang.

b. Sebaiknya kegiatan ECC dilaksanakan seminggu sekali untuk agar siswa tidak terlalu capek dan masih bisa melaksanakan kegiatan yang lain. Hal ini diungkapkan oleh salah satu peserta ECC.

"The English class is very pleasant, but it will be better to meet once a week. I feel object following the schedule".

c. Sedikit menggunakan Bahasa Indonesia agar siswa memahami makna untuk kata-kata sulit.

\section{KESIMPULAN}

Dari paparan diatas, bisa disimpulkan bahwa siswa menunjukkan respon yang positif kegiatan ECC dapat dijadikan sarana untuk latihan untuk meningkatkan kemampuan bahasa Inggris. Selama kegiatan tutor menyiapkan beberapa kegiatan yang didukung dengan game, media, dan teknik yang menyenangkan sehingga dapat meningkatkan motivasi, rasa percaya diri, dan penguasaan Bahasa Inggris. Terkait dengan kendala yang terjadi selama kegiatan ECC dapat dijadikan sebagai bahan evaluasi untuk mensukseskan program ECC selanjutnya. 


\section{DAFTAR RUJUKAN}

Ellis, R. 1994. Second language acquisition. Oxford: OUP.How to introduce yourself in English. https://www.youtube.com/watch? $v=z K Z 1 Y 6 o H 8 F c$

Istirokhah. (2010).Improving Students' Understanding on Simple Past Tense through Songs (A Classroom Action Research with the Second Year Students of SLTP NU Sunan Abinowo Kendal in the Academic Year of 2010/2011). Unpublished thesis. Semarang: Tarbiyah Faculty Walisongo State Institute for Islamic Studies.

Mega, (2012). The use of song lyrics in improving students' grammar mastery of past tense: a quasi-experimental study at the second grade of one senior high school in Cianjur. Unpublished thesis. Bandung: Universitas Pendidikan Indonesia.

Kurniawan, M., Herpratiwi, Purnomo, E. (2015).Evaluasi program English Club. Jurnal Teknologi Informasi Komunikasi Pendidikan, 3(5), pp.1-10.

Kurniasih \& Umamah, A. (2013). Authentic Materials: A promising way to the teaching of grammar. Parallel session presented at the International TEFL Conference, Sebelas Maret University 